Table I

Mean Attitude Scores

\begin{tabular}{lrrrr} 
& \multicolumn{2}{c}{ Males } & & Females \\
\cline { 2 - 5 } Birth Order & Low Fear & High Fear & Low Fear & High Fear \\
\hline Later Born & $8.60(5)$ & $32.43(7)$ & $27.75(8)$ & $13.43(7)$ \\
First Born & $19.43(7)$ & $11.20(5)$ & $38.75(4)$ & $19.80(5)$ \\
\hline
\end{tabular}

Note-The number of $S s$ in each condition is shown in parentheses.

the control issue did not differ across communications. Therefore, a difference score between each S's total opinion score on the experimental issue and the control issue was calculated to provide a sensitive measure of attitude change. The data were then analyzed as a fear by birth order design separately for each sex. The mean attitude change and frequency of $S s$ in each of the experimental conditions are shown in Table 1. As shown in Table 1, the pattern of the means was very different for males and females. For males, later-born Ss under high-fear conditions were more persuaded than were first-born Ss. However, the direction was reversed in the low-fear condition, with first-borns more persuaded than later-borns. The Fear by Birth Order interaction was significant $(F=5.58, \mathrm{df}=1 / 20, p<.03)$. Neither of the main effects was significant.

The results for males were almost identical to the results Helmreich, Kuiken, \& Collins (1968) found for their male Ss. In their study, as in the present study, later-born $\mathrm{Ss}$ under high fear showed considerably more change than any other group. Similarly, in their study, there was very little difference between first borns and later borns under low fear. In the present study, the difference between first borns and later borns under low fear is only half of the comparable difference in the high-fear condition.

When the results for females are considered, however, there is no evidence of an interaction $(F=.08, \mathrm{df}=1 / 20$, $p>.50$ ). Females in both birth-order conditions were more persuaded under low fear. The main effect of fear was significant $(F=4.28, \mathrm{df}=1 / 20, p<.05)$, even with the small number of first-born females in the low-fear condition. The main effect of birth order was not significant. Thus, females reacted to the situation very differently than did males.

An analysis of the recall scores indicated that there were no differences in learning between the experimental conditions for either sex. Also, there were no differences on any of the seven general evaluation rating items. A "fear" score was derived for each $S$ by summing the ratings on six of the mood words. This score was intended as a rough check on the fear manipulation. Analyses of these ratings did not reveal any differences between conditions. Perhaps the lack of differences on this measure was due to the fact that $S$ s had completed the other ratings first and were satiated with the rating task.

The results of the study confirm Helmreich's previous findings that a source of fear extraneous to the content of a communication does affect persuasibility. By implication, these results indicate that the generally positive relations found in studies using fear-arousing communications may be attributed to variation in the fear appeal rather than to changes in the content of the communication. At the same time, the present results indicate that the effects of fear on persuasibility are not simple. The interaction of birth order with fear for males implicates personality variables in the relationship, although it is unclear at present what those variables are. The results for females show an inverse relationship between persuasion and fear. Actually, the data for females might be
RONALD E. SMITH, University of Washington, Seattle, Wash. 98105, and BARRY L. MEADOW and THOMAS K. SISK, Purdue University, Lafayette, Ind. 47907

Ss, differing in the degree to which they were led to believe that a stranger's attitudes were similar to their own, observed the stranger (a confederate) in a verbal learning situation in which shock was supposedly administered for incorrect responses. The confederate's performance interpreted as supporting Janis \& Feshbach's (1953) defensive avoidance hypothesis. It appears that the search for a simple fear-arousal/persuasion relationship will not be successful. Very likely the joint effect of fear and (perhaps many) other interacting variables will have to be considered to make sense out of this area of research.

\section{REFERENCES}

HELMREICH, R, KUIKEN, D., \& COLLINS, B. Effects of stress and birth order on attitude change. Journal of Personality, 1968, 36, 466-473.

JANIS, I., \& IESHBACH, S. Effects of fear-arousing communications. Journal of Abnormal \& Social Psychology, 1953, 48, 78-92.

MoGUIRE, W. J. Inducing resistance to persuasion. In L. Berkowitz (Ed.), Advances in experimental social psychology. Vol. 1. New York: Academic Press, 1964. Pp. 191-229.

McGUIRE, W. J. Attitudes and opinions. Annual Review of Psychology, 1966, 17, 475-514.

McGUIRE, W. J. The nature of attitudes and attitude change. In G. Lindzey and E. Aronson (Eds.), The handbook of social psychology. (2nd ed.) Vol. 3. The individual in a social context. Reading, Mass: Addison-Wesiey, 1969. Pp. 136-314.

SIGALL, H., \& HELMREICH, R. Opinion change as a function of stress and communicator credibility. Journal of Experimental Social Psychology, 1969, 5, 70-78. NOTE.

1. We are grateful to Mary Catherine DeLattre who served as the second $E$.

\title{
Attitude similarity, interpersonal attraction, and evaluative social perception
}

was programmed so as to be the same for all Os. Attitude similarity was positively related to both pre-and postobservation attraction ratings. High similarity and high attraction $S s$ rated the stranger's performance significantly more favorably and also exhibited a tendency to rate the shock supposedly experienced by him as being more painful than did low similarity and at traction $S$ s.

Byrne (1969) has summarized a long series of studies indicating a positive linear 
relationship between experimentally manipulated attitude similarity and interpersonal attraction. While this relationship has been repeatedly demonstrated in both between-Ss (Byrne, 1961) and within-Ss (Byme \& Nelson, 1965) designs, few attempts have been made to relate attitude similarity and attraction to other behaviors. The present study was designed to extend Byrne's methodology to an investigation of the relationships between attitude similarity (AS), interpersonal attraction, and the evaluative perception of an observed stranger's performance in a verbal-learning situation.

\section{METHOD}

The Ss were 44 male college students who were assigned randomly to two AS conditions. Ss were individually administered a questionnaire on which they indicated their attitudes toward 12 issues. $S$ was then presented with the responses on the same questionnaire of a stranger of S's sex and age. The stranger's responses had actually been generated by $\mathrm{E}$ to agree with S's on 2 of the 12 issues (low-AS condition) or on 10 of the 12 (high-AS condition). The measure of attraction was embedded in an Interpersonal Judgment Scale that $S$ was asked to fill out regarding the stranger after examining his attitude responses and consisted of the sum of S's responses on three 7-point rating scales concerning probable liking of the stranger, probable enjoyment of working with him, and probable enjoyment of having the stranger as a roommate. $S$ was then told that he would actually observe the stranger participating in another experiment and would be asked to make further judgments about him after the observation. A one-way-vision mirror was uncovered and an intercom was turned on, allowing $\mathbf{S}$ to observe and hear the stranger (actually a confederate of $E$ ) in an adjoining room. The $S$ was told that the stranger was about to be run in a learning experiment involving electric shock. $E$ then excused himself from $S$ and entered the adjoining room, where he attached a set of bogus electrodes to the confederate's right hand and told the latter to listen carefully to his instructions, which would be presented by tape recording. Following the confederate's instructions, which described the paired-associates learning task and which included a statement that each incorrect response would be followed by a brief electric shock, $S$ observed the confederate perform his task. Seven paired-associate items were presented verbally by tape recording, with the confederate giving his verbal response during a $2-\mathrm{sec}$ interval between the stimulus and response words. The confederate's responses were programmed to be the same for all Os and to conform to a standard learning curve across four trials. After each incorrect response, E activated a loud switch on an illuminated panel to which the confederate's electrode wires were attached, and the confederate jerked his hand as if he had been shocked. He was instructed to make no other bodily or facial movements. The confederate had no knowledge of which AS condition the 0 had been assigned to.

Following his observation of the stranger, $S$ was asked to again complete the Interpersonal Judgment Scale and also 7-point rating scales regarding (a) his evaluation of how well the stranger had performed on the task and (b) how painful he judged the electric shock delivered to the confederate to have been.

\section{RESULTS}

Consistent with the results of earlier studies, the Ss in the high-AS condition showed significantly greater preobservation attraction toward the stranger than did the low-AS group $[F(1,42)=16.26, p<.001]$. This relationship was maintained on the postobservation attraction ratings, with the high-AS group continuing to rate the stranger as more attractive $[\mathrm{F}(1,42)=7.01$, $\mathrm{p}<.02]$. While both AS groups showed slight increases in their attraction ratings after observing the stranger, the changes were not significant. The pre- and postobservation attraction means for the two AS groups are presented in Table 1 .

Of primary interest were the results involving the Ss' judgments of the stranger's performance and of the aversiveness of the shock supposedly delivered to him. The high-AS group rated the stranger's task performance more positively than did the low-AS Ss $[F(1,42)=6.48, p<.02]$. Further, when Ss in the two AS conditions were divided into high- $(\mathrm{N}=20)$ and low. $(\mathrm{N}=18)$ attraction groups on the basis of their preobservation attraction ratings of the stranger, the high-attraction group evaluated the stranger's performance more positively than did the low-attraction Ss $[F(1,36)=7.55, p<.01]$. With regard to the shock-intensity ratings, nonsignificant $(p<.20)$ trends were found for the high-AS and attraction Ss to rate the shoc.

Table 1

Pre- and Post-Observation Attraction Means for the Two Attitude Similarity Groups

\begin{tabular}{lcc}
\hline $\begin{array}{c}\text { Attitude } \\
\text { Similarity }\end{array}$ & $\begin{array}{c}\text { Pre- } \\
\text { Observation }\end{array}$ & $\begin{array}{c}\text { Post- } \\
\text { Observation }\end{array}$ \\
\hline High & 15.45 & 15.81 \\
Low & 12.68 & 13.45 \\
\hline
\end{tabular}

Table 2

Performance Evaluation and Shock Aversiveness Means for the Attitude Similarity and Attraction Groups

\begin{tabular}{lcc}
\hline $\begin{array}{c}\text { Attitude } \\
\text { Similarity }\end{array}$ & Performance & Aversiveness \\
\hline High & 4.68 & 3.59 \\
Low & 3.95 & 3.18 \\
Attraction & & \\
High & 4.65 & 3.60 \\
Low & 4.00 & 3.22 \\
\hline
\end{tabular}

supposedly experienced by the stranger as being more painful. The performance-evaluation and shock-aversiveness means for the AS and attraction groups are presented in Table 2 .

\section{DISCUSSION}

To the extent that evaluative judgments reflect perception, the results of the present study suggest that attitude similarity and attraction can affect evaluative social perception. In spite of the fact that all Ss were exposed to the same stranger and to identical task performance on his part, the high-AS and attraction Ss consistently rated the stranger's performance more favorably. Of additional interest is the fact that the preobservation attraction differential in the two AS groups maintained itself even after the Ss were actually exposed to the stranger. This finding suggests that initial information regarding attitude similarity exerts an effect of some stability on attraction.

The results of the shock-intensity ratings, while failing to attain significance, are of some interest, since they suggest the possibility that similarity-mediated attraction may be capable of affecting perception of reinforcement variables. A clear demonstration of such a phenomenon would have obvious implications with regard to vicarious reinforcement and learning processes.

On a methodological level, the results of the present study indicate that the experimental manipulation of attitude similarity is a dependable and economical method for producing differences in attraction which may, in turn, be employed as an independent variable in studies involving a variety of social behaviors.

\section{REFERENCES .}

BYRNE, D. Interpersonal attraction and attitude similarity. Journal of Abnormal \& Social Psychology, 1961, 62, 713-715.

BYRNE, D. Attitudes and attraction. In L, Berkowitz (Ed.), Advances in experimental social psychology. Vol. 4. New York: Academic Press, 1969. Pp. 35-89.

BYRNE, D., \& NELSON, D. The effect of topic importance and attitude similarity-dissinilarity in a multistranger design. Psychonomic Science, 1965, 3, 449-450. 